\title{
Design and Application of Central Examination System for Life-Long Learning with Web-Based Distance Education*
}

\author{
Hamit AKSOY1 , Hasan ERBAY², Hakan KÖR3 \\ ${ }^{1}$ Lecturer, Hitit University, Sungurlu Vocational School, hamitaksoy@hitit.edu.tr \\ ${ }_{2}^{2}$ Prof. Dr., Kirlkkale University, Faculty of Engineering,Department of Computer Engineering, hxe68@yahoo.com \\ 3 Lecturer, Hitit University, Distance Education Center, hakankor19@gmail.com \\ *This article was presented at the 1st International Conference on Lifelong Education and Leadership, in \\ Olomouc, Czech on October 29-31, 2015.
}

\begin{abstract}
In our age, information and communication technologies are intensely made use of to make a connection between student and teacher, and to establish an educational environment appropriate to the requirements of this era and society, in distance education. The fact that student, teacher and teaching material are distant from each other, as a factor that reveals the difference between distance education and traditional education, forces to use different methods in order for the evaluation activities to be conducted much more effectually. However, the reliability of on-line examinations is discussed in cases where important documents like certificates, diplomas, etc. are to be given by universities and other institutions that provide life-long distance learning. Among the reasons of this are the difficulty of detecting whether the person sitting for an exam is one who should sit for that exam, and whether he/she uses the instruments apart from the ones allowed for him/her use in the exam. For this reason, the universities providing distance learning are obliged to use central examination system in order to evaluate the success of students even though they had given the lessons to their students by means of web-based distance education method. Distance learning departments of many universities in our country have established more recently. Most of those departments haven't got a substructure based on central examination system. A sample application of central examination system (DECES) which Distance Learning Departments of the Universities can use, has been developed and introduced with this study. Adequate and inadequate aspects of it have been specified thereby analyzing the systems existing firstly. Afterwards, an appropriate platform was searched for encoding of DECES and open-source programing PHP language and MySQL data-base have been chosen. The tables in the system were formed using relational data-base model and encoding was made using the properties of object oriented programming.
\end{abstract}

Keywords: Lifelong Learning, Distance Education, Evaluation

\section{Introduction}

Since 2oth century, the world has experienced highly significant changes and transformations socially, economically and culturally. These changes in question require individuals to go through a lifelong education and to adapt themselves to their society and to such rapid changes. It is possible for the individual to maintain a life in coherence with the society and to follow developments in his occupation closely if he renews himself. Individual's constant renewal is only achievable with lifelong learning. Since "lifelong learning" is a concept that can occur wherever an individual exists and eliminate any kind of limitation such as location, time, age and level of education; it has gained priority among the works carried out in the field of education in the world and therefore various works have been carried out pertaining to the concept of lifelong learning. Education should prepare the youth not only for their future jobs but also for constant development and new situations, production methods and conditions (Güleç at al., 2012). 'In parallel with the increase of educational requirements of adults, significance and value of lifelong learning and distance education have gained wider adoption' (Fourie, 2001:112).

Education is among the fields where changing conditions, developing methods and techniques are applied the most. There are a certain number of ongoing problems in countries' education systems basing on their level of development. The fact that traditional solution seeking fails to resolve these problems and advancing technologies provide charming opportunities directed social education systems to new quests such as lifelong distance education. The reasons that require constitution of education approaches referred as in-service training, training by post, school tv, open education faculties and online training until today are also the very reasons that set up a structure for web-based lifelong distance education. In today's world where communication and information technology are inseparable parts of individual and corporate life, technological skills are continually advancing, corporate processes are rapidly moving to 
electronic environment and therefore can obtain more efficiency out of the processes (Odabaş, 2003). Certain new training applications carried out through the internet have removed the restrictions concerning time and place in education and enabled the student to access the information whenever and wherever she wants (Yiğit, Yıldırım \& Özden, 2000). Due to technological changes and opportunities, the role of the school has changed. Therefore, depending on distance learning programs, new methods that can be summed up as "bringing the school to learner, instead of taking the student to school" have been developed (Georgescu, 2005). Another educational application benefiting from such opportunities of technologies has been distance education (Young \& Lewis, 2007).

\section{Types of Distance Education}

Distance education types can be considered as such:

A. It is the situation in which instructor and student do not meet in any way, in other words the situation in which education is carried out independent from time and place. To distribute course content in this type of distance education, World Wide Web (WWW) and for communication, e-mail can be used.

B. It is the situation in which education is carried out completely independent from place but halfdependent on time. In this kind of distance education, interactive Web instruments such as Internet Relay Chat (IRC) can be used in order to solve a certain problem or to answer a question included within the scope of thelesson.

C. It is the situation in which education is carried out completely independent from place but halfdependent on time. Video conference system where questions are asked and answered mutually can be used in this type of distance training works.

D. It is the situation where education is carried out face to face in a class environment with electronic discussion support in a campus.

E. It is the situation where a part of education is carried out face to face (dependent on place/time) and another part of it is provided as distance education (independent from time/place). Generally, while examination stages in the beginning and ending of the program are carried out face to face; interim stages are carried out as stated in article A.

\section{Aims}

In this project, a beneficial software which comprehends the facility of pursuit of the management process and transactions of exams in terms of distance education. This conception has been grounded on the idea that the profit of work force and time by implementing smoothly the accommodation of existing students into the locations and the determination of exact and suitable attendants by associations with this project, which requires a counterproductive endeavor and precious time in order to provide a harmonic atmosphere of exam managers throughout the exam span.

\section{Centralized System Examinations}

Today, certain universities provide web based distance education through private and public bodies. Evaluating whether the responsibilities regarding the provided education are fulfilled is among system's responsibilities. The success of these trainings is based on whether they give decent results in terms of student, instructor and school. It is a fact that assessment and evaluation techniques have an absolute effect on the success of the provided training. For this reason, the assessment and evaluation technique to be used should be determined basing on the type and application method of the training. As stated above, universities providing lifelong distance training service might want to utilize centralized examination system instead of techniques such as online examination method etc. due to unsuitable conditions; moreover, they sometimes are obliged to. As in formal training, since they feel freer because there is no instructor supervision, students might stack the deck in distance education examinations (Ergüzen, 2012). According to Ergüzen, student might cheat using different sources or people while having online examination and this fact weakens reliability of the system. There are numerous academic publishing including reasons of cheating in exams, methods of cheating and relevant statistics (Ergüzen, 2012).

The number of universities founded in our country within the last decade is 114 (CHE, 2015). Distance education unit of many of these universities has been founded recently. The fact that web based distance education system is perceived and applied as uploading lecture notes to internet decreases the quality of education. Such units need web based software where they can follow and carry out distance education and centralized examination system operations. Many universities tried distance training without analyzing whether their infrastructure is ready for distance education, centralized or online examination system. In the meantime, they had to receive support from other universities or purchase special software in order to carry out their centralized examinations. In our work, an application named DECES is 
developed, its benefits for universities are told, improvable matters are mentioned and suggestions and advices are given for the universities willing to develop and utilize similar applications.

\section{Distance Education Central Examination System-Deces}

The main feature of DECES is that information exchange between units and individuals using the system can be maintained easily, simply and regularly. There are two significant elements that system is required to perform. The first element is distribution of students to rooms in order to determine in which exam room the students will take the activated exam and the second is distribution of proctors to rooms in order to determine in which room and position the proctors will be placed. There are 4 types of user in DECES, which are administrators, unit users, instructors and students. All users access to the system through the same login screen (Fig. 1), then each user type logging in the system accesses to a different welcoming page.

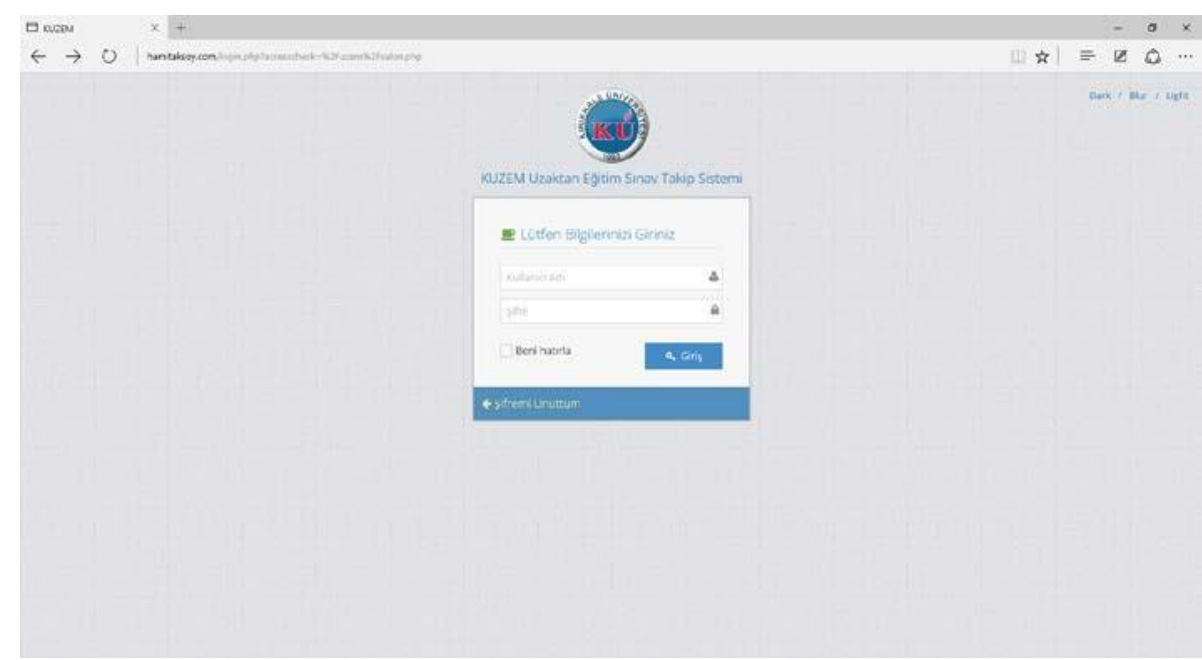

Figure 1. Homepage

Administrators can carry out all identification required for a distance training centralized examination system through the web page (Fig. 2) that is opened after logging in the system. Administrator can identify units of university, exam rooms in units, types of exams to be held, for which lessons exam will be held and perform user identifications.

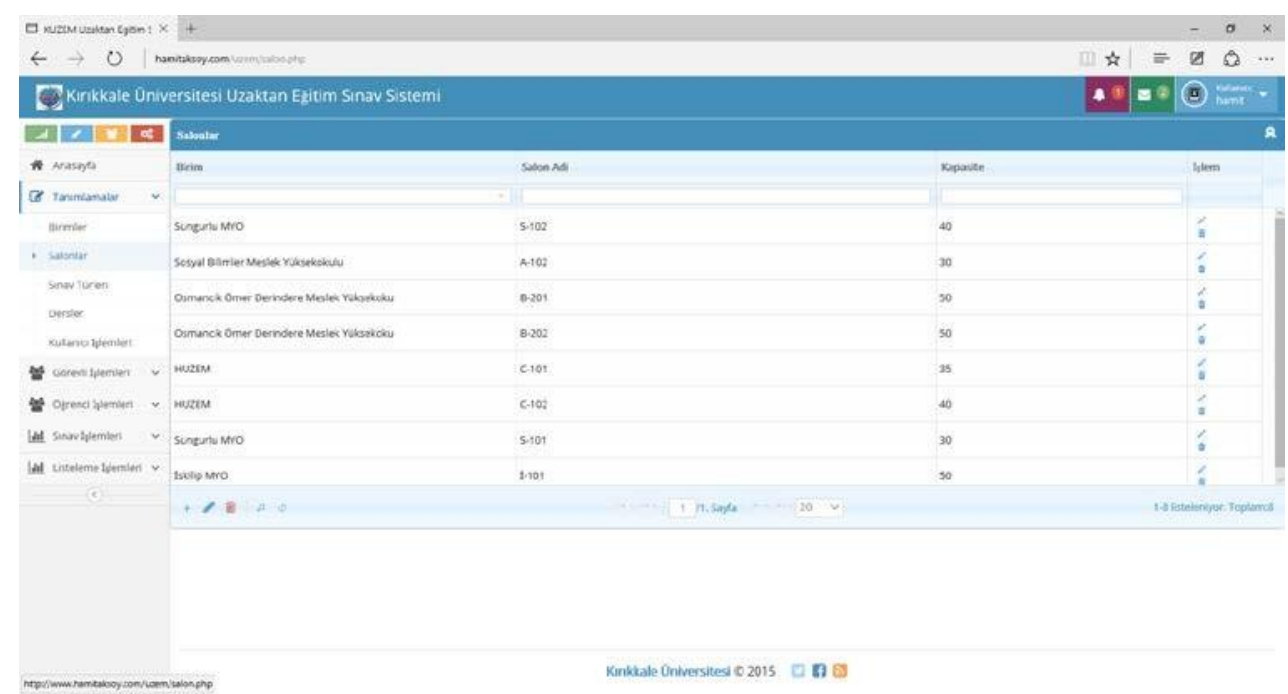

Figure 2. Administrator Interface.

Administrator can determine personnel in unit and assignment types of the personnel to take charge in the exam through the proctor operations menu. Via student operations menu, administrator can display and edit which unit and department the students study in, lessons selected by student and student's grades of distance education exams. He can also transfer data of distance education students studying in 
the university to DECES through student affairs automation web-service or by retrieving from Microsoft Excel. Exam periods, exams, which personnel take charge on which duty in exams can be displayed and edited through examination operations menu. Also with this menu, administrator can check room capacity in units and whether student number is suitable for the exam to be held. $\mathrm{He} / \mathrm{she}$ can determine in which units the exam should be held in multiple sessions and increase the number of sessions for such units. In developed algorithm, it is paid attention to prevent server from straining computers and to write codes that will reduce distribution time during the operation of student distribution to exam rooms. For, the number of students receiving distance education in some universities is pointed out to be over several 10.000 and distribution of such numbers to exam rooms can take long. The number of students receiving all of their lessons through distance education in 2014-2015 Academic Year in Turkey is 59,282 in total; 34,754 of them being men and 24.528 of them being women (CHE, 2015). Thanks to the developed algorithm, all parameters such as units, room capacities in units, numbers of students and exam session numbers were considered during distribution process; therefore unnecessary loops were avoided and coding was performed with a high performance. Distribution operations can be performed both collectively for all units of university and separately for each unit (Fig. 3).

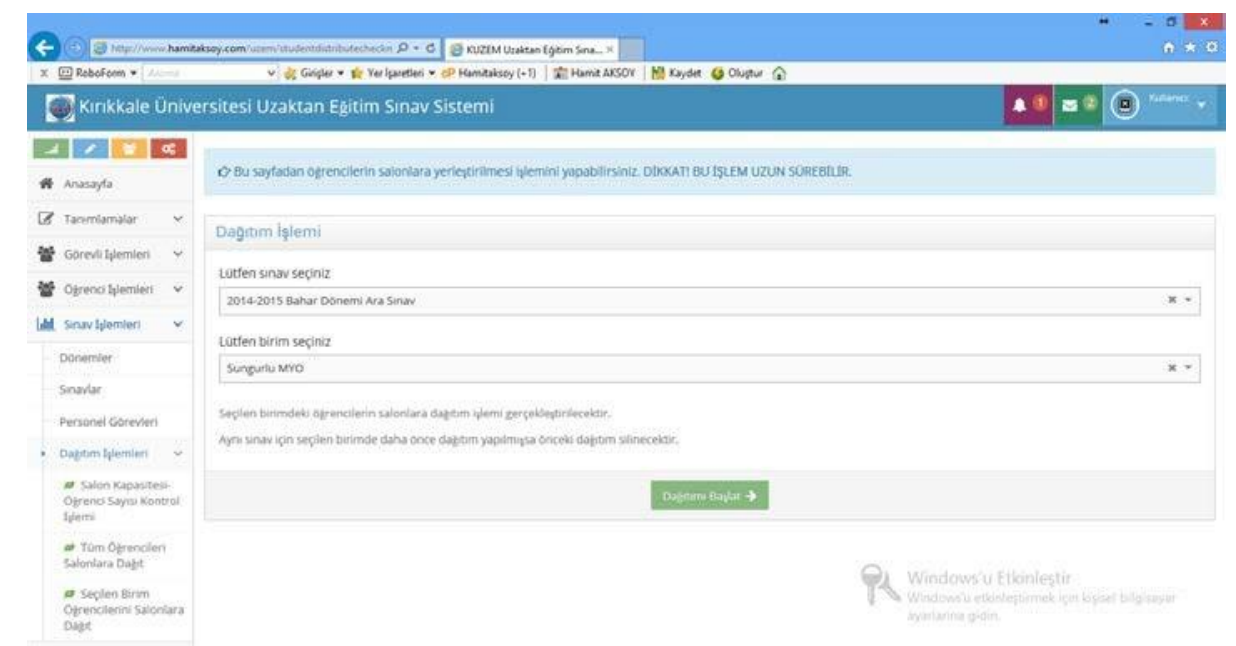

Figure 3. The first screen used in distribution of students to rooms

Unit users, being another type of user, can perform identifications concerning the unit over the system such as exam rooms, room capacity, instructors and departments. They can display distance education lesson selected by students, student, exam and session details and distribute exam duties to personnel manually. In some universities which make payment to their personnel for exam duties and have a large number of personnel to assign when performing personnel assignments, it might be desired to give exam duties automatically basing on whether personnel want exam duty or not. In some other universities, distribution of duty is performed regardless of personnel's willingness to take exam duty since the number of personnel that can be assigned to the exam is insufficient or the personnel are not given payment for exam duty. Even if the system is designed suitable to manual distribution of exam duty, it can be enabled to perform automatic distribution with several simple changes. (Note: Unit users can perform these operations for the exams activated by the administrator).

After user-type users logged in the system, instructors can demand exam duty in exams activated by the administrator. They can control whether they are given duty for an upcoming exam and if they are given duty, they can display details of duty (the exam room they are assigned to, date and time of exam, type of duty etc.) and their pastduties.

After a user logs in as user-type, which is created for students, she/he can control personal information, change password, display in which room and desk she/he will take the activated exam and personal success evaluation results in distance training lessons. The student can display his exam paper online and can object to his grade over the system.

\section{Methods}

In this work, web-based centralized examination system application is developed and presented to Hitit University Distance Education Centre (HUDEC) and Kırıkkale University Distance Education Centre 
(KUDEC). First of all, the characteristics required in a centralized examination system for a distance education unit are determined. Similar software that is already in use is analyzed. However, we did not have the chance to analyze a large number of software because demo of many of this software is not open to share and investigation of the software is not allowed due to security matters. Model of this research is screening model. Later, a research is conducted for a suitable platform for coding of DECES and open coding PHP language and Mysql database are chosen. Database structure is constituted as below (Fig. 4). It is endeavored to use up-to-date web instruments during design and coding process.

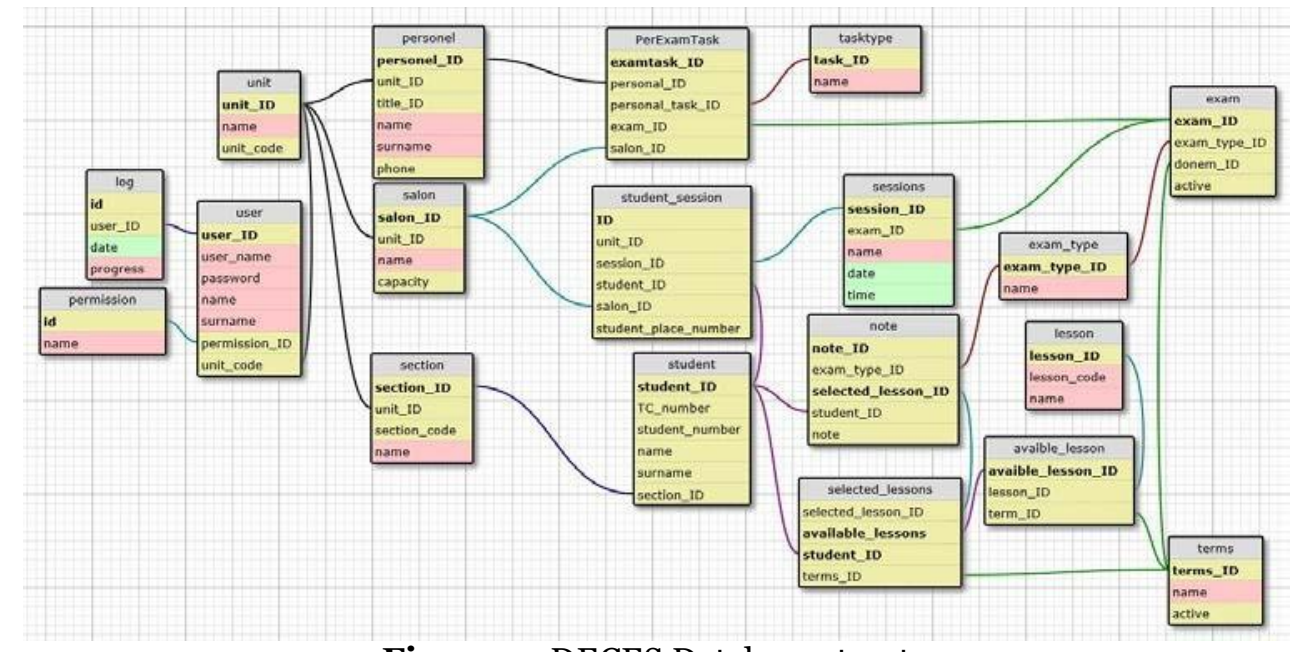

Figure 4. DECES Database structure.

\section{Discussion}

Although many distance education units apply centralized system examinations, they do not possess the quality software where they can follow their works and operations. While some universities use professional software, some other either meet their requirement by purchasing external service or performing their operations manually. Especially in the communication between distance education unit and other units; instead of a web based software, methods that do not have a certain standard such as attaching required data and files to e-mail are used. For instance, distance education unit might demand data of personnel demanding duty, room number and capacity from other units. Data sharing in this email traffic among units will lack desired speed and be irregular. Furthermore, to perform these operations manually while determining exam duties and assigned rooms of the personnel that will take duty in the exam might result in some complications.

\section{Results}

DECES and similar software will minimize such complications and flaws in data communication. At the same time, the fact that students can display their exam papers and evaluation results through the internet both increases reliability of the exam and provides the chance to correct the mistakes in evaluations on time.

In order for such software to become widespread and be used more efficiently in universities, universities should publish demos of their works that are for the public weal such as e-learning, online exam, centralized examination system and share their experiences with other universities. This consequence obviously illustrates that the approaches of the utilization of multifarious online services which have been centered around the needs of each individual could reduce the misconceptions in terms of online transactions.

\section{Conclusion}

DECES is a web based centralized examination system that enables universities, which provide lifelong distance education, to perform centralized exams for their students. The system is designed to provide a pre-understanding to distance education units of universities about which features should be present in centralized examination system of universities providing distance education in Turkey.

During, before and after development of such systems, opinions of student, instructor, unit and administrative should be received. 
It should be taken into account that the methods to be conducted by universities in distance education might differ basing on time and the unit that will apply the method. For instance, it is necessary that the personnel to be assigned are able to choose their duty type when demanding exam duty or to enter the information whether they are willing to take exam duty or not. In case of need, the administrator should be able to decide whether duty distribution of personnel in unit is performed automatically or manually and to adjust this operation parametrically over the system. For example, administrator might demand the units to enter data of their personnel to be assigned to rooms to the system manually.

Test works of designed software are in progress in Hitit University Distance Education Centre. If desired results are obtained, it is aimed to share these results with all higher education institutions. By this means, there will be no need to make heavy budget expenses reserved for software prices and national economy will be contributed.

\section{References}

CHE, (2015). Council of Higher Education, https://istatistik.yok.gov.tr. (Retrieved September 01,2015) Ergüzen, A.(2012). Kullanıcı Etkileşimli Öğrenim Yönetim Sistemi (ÖYS) Tasarımı, Doktora Tezi, Yükseköğretim Kurulu Başkanlığı Tez Merkezi.

Georgescu, M. (2005). The future of e-learning: Designing tomorrow's education. Collaborative support systems in business education. From <http://ssrn.com/abstract=904201>. (Retrieved July 08, 2015)

Güleç,İ., Çelik,S., Demirhan,B., (2012). What Is Lifelong Learning? An Evaluation on Definition and Scope, Sakarya University Journal of Education, 2/3 (Aralık /December 2012) ss. 34-48.

Odabaş, H, (2003). Internet Tabanlı Uzaktan Eğitim ve Bilgi ve Belge Yönetimi Bölümleri. Türk Kütüphaneciliği, vol. 17, n. 1, pp. 22-36. [Journal article (Print/Paginated)].

Yiğit, Y., Yıldırım, S., Özden, M.Y. (2000), Web Tabanlı İnternet Öğreticisi: Bir Durum Çalışması, Hacettepe Üniversitesi Eğitim Fakültesi Dergisi, 19, s.166-176.

Young, A., Lewis, C. W. (2007). Teacher Education Programmes Delivered At A Distance: An Examination of Distance Student Perceptions, Teaching and Teacher Education, Article in Pres. 